\title{
Histórias de vida, histórias de formação: narrativas de/sobre formação de integrantes de um grupo de estudos e pesquisas
}

\author{
Caio Corrêa Derossi* \\ Karen Laíssa Marcílio Ferreira** \\ Mirelle Barbosa de Souza**
}

\begin{abstract}
Resumo:
O presente ensaio teórico-metodológico, de natureza qualitativa e de abordagem bibliográfica e empírica, objetivou analisar e compreender sobre os aspectos formativos da docência, inscritos em seis narrativas de integrantes do Grupo de Estudos e Pesquisas Formação do Educador e Práticas Educativas (FORMEPE), ligado ao Programa de Pós-Graduação em Educação, curso de Mestrado, da Universidade Federal de Viçosa. A partir de uma dinâmica motivada pela discussão acerca a formação de professores em um prisma teórico-metodológico das pesquisas narrativas, partiu-se das histórias e das experiências compartilhadas pelos sujeitos, para se discutir frente ao conhecimento produzido e a literatura especializada, os movimentos de formação, de desenvolvimento e de aprendizagem profissionais, relacionando os componentes micro e macro sociais. Então, pode-se observar a potencialidade de se refletir os processos formativos dos professores partindo das trajetórias de vida e formação narradas.
\end{abstract}

\section{Palavras-chave:}

Profissão docente. Narrativas. Formação de professores.

\begin{abstract}
:
The present theoretical-methodological essay, of a qualitative nature and with a bibliographic and empirical approach, aimed to analyze and understand the formative aspects of teaching, inscribed in six narratives of members of the Study and Research Group Educator Training and Educational Practices, linked to the Graduate Program in Education, Master's course, Federal University of Viçosa. Based on a dynamic motivated by the discussion about teacher training in a theoretical-methodolo-
\end{abstract}

\footnotetext{
* Licenciado em História e mestrando no Programa de Pós-Graduação em Educação, ambos pela Universidade Federal de Viçosa. E-mail: derossi.caio@gmail.com. ORCID iD: https://orcid.org/0000-0001-9762-7392.

** Licenciada em Pedagogia pela Faculdade da Serra/MULTIVIX e mestranda no Programa de Pós-Graduação em Educação da UFV. E-mail: karenkaispa@gmail.com. ORCID iD: https://orcid.org/0000-0003-4469-3403.

*** Licenciada em Ciências Biológicas e mestranda no Programa de Pós-Graduação em Educação, ambos pela UFV. E-mail: mirelle.souza@ufv.br. ORCID iD: https://orcid.org/0000-0001-7224-7641.
} 
gical prism of narrative research, we started from the stories and experiences shared by the subjects, to discuss the knowledge produced and the specialized literature, the movements of training, development and professional learning, relating the micro and macro social components. Then, it is possible to observe the potential of reflecting the teachers' training processes starting from the narrated life and training trajectories.

\section{Keywords:}

Teaching profession. Narratives. Teacher training.

\section{Palavras iniciais}

O presente ensaio teórico é resultado das discussões desenvolvidas no Grupo de Estudos e Pesquisas Formação do Educador e Práticas Educativas (FORMEPE), no âmbito do Programa de Pós-Graduação em Educação da Universidade Federal de Viçosa (PPGE - UFV). O grupo vem desenvolvendo de forma sistemática atividades, leituras e debates que visam analisar e compreender as contribuições da perspectiva teórico-metodológica das narrativas nas pesquisas no campo educacional e na formação de professores.

O estudo compartilha, de forma específica, seis narrativas de/sobre a formação de seus integrantes, a saber: pós-graduandos, egressos do PPGE, professores universitários e da educação básica, produzidas por eles, em uma dinâmica, coordenada pelos autores do artigo. Os nomes dos sujeitos que compõem o texto são fictícios, em observância aos princípios da ética em pesquisa e da confidencialidade das identidades dos participantes. A atividade visava a congregar uma exposição conjunta dos projetos de pesquisa dos propositores da dinâmica, que versavam de formações inicial e continuada, através de um convite a participação dos demais interlocutores, por meio da produção de uma narrativa acerca de um momento considerado marcante de sua formação.

Nesse sentido, as narrativas serão analisadas juntamente com a apresentação de um curto perfil biográfico de cada sujeito, o qual contempla a idade, a quantidade de anos de sua escolaridade, o nível de escolaridade dos pais, os tipos de estabelecimentos de ensino que estudou durante a vida, a titulação acadêmica e a atuação profissional. O entendimento é que tal caracterização corrobora a compreensão das narrativas retratadas. Os nomes dos sujeitos são fictícios, respeitando as normativas éticas em relação à participação de seres humanos em pesquisas.

Nos últimos anos, de forma cada vez mais emergente, as áreas de estudo ligadas à educação reconhecem a relevância das contribuições teórico-metodológicas das narrativas para as investigações e para o desenvolvimento profissional da docência. Segundo Prado e Soligo (2003) as narrativas são constituídas, ao menos, por dois elementos principais: um enredo, uma história sequencial de fatos e uma qualificação implícita sobre o que é narrado. De acordo com o que é presente na literatura especializada, as narrativas se mostram potencialmente como possibilidades para se pensar a pesquisa, a formação e o desenvolvimento profissional docente, a partir da construção de gêneros textuais como os memoriais de formação, os cadernos ou diários de campo, as entrevistas narrativas, as notas de aula, as cartas pedagógicas, entre outras.

Para embasar as discussões, contamos com referências especializadas nos estudos das narrativas, e com ênfase no campo educacional, principalmente em interface com a formação de professores, como: Passeggi (2010), Souza (2012), Zabalza (2004), Bolívar (2002), Benjamin (1993) e Nóvoa (1992). A estruturação do artigo é dividida em quatro seções, excetuando-se a primeira, que é uma introdução. A parte inicial trará apontamentos acerca do uso das narrativas na investigação sobre formação de professores. A segunda destacará alguns pontos da metodologia do trabalho com as narrativas e alguns instrumentos para a pesquisa. A terceira seção trará os elementos das narrativas dos sujeitos, traços dos seus perfis biográficos e análises acerca da formação. A quarta e última parte referirá as considerações finais da proposição. 


\section{A narrativa como uma metodologia de pesquisa e formação de professores}

As narrativas permeiam toda a história do ser humano e, em função dos sujeitos que as produzem e de sua localização socioespacial, os contextos diversos devem ser considerados para o melhor entendimento dos enredos contados. O contar e o ouvir histórias são características que humanizam e diferem os homens e as mulheres de outros animais e, em alguns casos, principalmente aqueles marcados pela cultura, a narrativa ocupa um papel central e quase involuntário, na transmissão intergeracional de saberes e costumes através da cultura oral. As narrativas se relacionam entre suas partes e conferem materialidade às histórias contadas. Nesse sentido, Delory (2012, p. 82) afirma que “[...] portanto, a narrativa não é apenas o produto de um 'ato de contar', ela tem também um poder de efetuação sobre o que narra”. Assim, para além da história contada, as narrativas demonstram as formas de entender e de organizar o mundo.

Com relação aos interlocutores, ouvintes dessas narrativas, a postura esperada é de escuta sensível e de diálogo, de construção coletiva frente ao que é narrado. Tal postura encaminha para o reconhecimento de que as histórias e a própria narração são conferidas de dinamicidade e de teias complexas de vivências, de experiências e de atuações variadas dos sujeitos. Nessa direção, o interlocutor não é um ouvinte passivo, mas um sujeito que se relaciona, reage e participa da história contada.

Ressalta-se que o processo de rememoração compõe as narrativas, uma vez que, a memória tendo por características a flexibilidade, a relação com outro e as marcas pessoais, possibilitam aos sujeitos recontar e reinventar suas histórias, refazendo trajetórias, resistindo a alguns fatos e abrindo possibilidades distintas para a sua vivência. Nesse sentido, Galzerani (1999), como Benjamin (1993) entendem a memória como experiência vivida. Para Galzerani (1999), o processo de rememoração mobiliza que se lembre de fases antes esquecidas no decorrer das trajetórias, uma vez que a memória é entendida como espaço de intercruzamento da lembrança, do presente, do passado e da projeção futura. Portanto, narrar é imergir na própria trajetória e compor a história da vida através das experiências privadas, públicas, representações e imaginários dos espaços e das relações que os sujeitos convivem.

É importante destacar que o processo de rememoração não é homogêneo, lógico ou cronológico, já que vários contextos e acontecimentos são tensionados e mesclados, lembranças e esquecimentos emergem junto a impressões e fatos de contextos específicos. Considerando esse contexto descrito, pode-se considerar o docente como um narrador, agente, protagonista da sua trajetória e da sua formação. A escolha pela narrativa é subsidiada em Benjamin (1993, p. 201) quando o autor afirma que "[...] narrador retira da experiência o que ele conta [...]", entendendo, como o autor, o sentido experiencial sendo a matéria prima para as narrativas. Nesse sentido, as experiências vividas pelos professores vão se mesclar, compor e trocar com outras vivências da vida e da formação desses profissionais. Nessa direção, Souza (2012, p. 46) aponta que "[...] narrar histórias e contar a vida caracteriza-se como uma das possibilidades de tecer identidade, de compreender como nos tornamos professores e das configurações que nos são forjadas nos nossos percursos de vida-formação". Conforme destacam Connelly e Clandinin (1995, p. 11), as narrativas, mesmo quando enfocadas para as discussões sobre formação de professores, elas também assumem um caráter investigativo, já que, segundo os autores:

A investigação narrativa é cada vez mais usada em estudos de experiência educacional. Tem uma longa história intelectual dentro e fora da educação. A principal razão para o uso da narrativa na pesquisa educacional é que os seres humanos são organismos contadores de histórias, organismos que individual e socialmente vivem vidas relacionadas. (CONNELLY; CLANDININ, 1995, p. 11, tradução nossa).

As narrativas, como destacam Connelly e Clandinin (1995) e Souza (2012) em suas investigações e que concordamos nesse texto, é que elas são uma metodologia de formação de professores, enfatiza que o desenvolvimento profissional seja amparado nas experiências e nos saberes construídos ao longo da vida e da prática profissional. Nesse sentido, são pensadas novas formas e novos contextos de aprendizagem da docência, encaminhando para o entendimento que as abordagens (auto)biográficas e das narrativas, junta- 
mente com as histórias e trajetórias de vida, constituem como lente e matéria profícuas para a reflexão das práticas profissionais, a formação enquanto docente, a elaboração e consolidação de novos saberes, que partem da sistematização da vida vivida em suas variadas esferas. Assim, quando as narrativas são pensadas em contexto de formação e desenvolvimento do professor, tal sujeito é considerado de forma multifacetada, sendo autor, ator e narrador das histórias formativas contadas. Os professores, no caso, não narram seus desafios e suas práticas exitosas de forma localizadas, segregadas. Eles agregam elementos de suas trajetórias escolares, educativas, não coevas ou relacionadas ao fato em si, o que demonstra a riqueza de análises sobre a formação e as trajetórias, as diferentes perspectivas e as trocas significativas no fazer docente.

Goodson (1992) considera que ouvir as vozes dos professores possibilita entender os pontos convergentes entre os aspectos da vida particular e da coletividade, como também a articulação entre os contextos e a constituição pessoal e profissional do sujeito. Para além disso, as narrativas permitem entender as conexões entre como as trajetórias dos sujeitos e suas práticas, como os caminhos e itinerários escolhidos para o desenvolvimento profissional. Nessa mesma direção, Abrahão e Passeggi (2010, p. 61) afirmam que

[...] o uso de narrativas [...] em contextos de formação inicial, e continuada, ancora-se no pressuposto dessa automização, no sentido em que o ato de explicitar para si mesmo e para o outro os processos de aprendizagem, adotando-se um posicionamento crítico, é suscetível de conduzir a pessoa que narra à compreensão da historicidade de suas aprendizagens e, portanto, de autorregular seus modos de aprender num direcionamento emancipador.

Conforme apontado por Abrahão e Passeggi (2010), as narrativas colaboram para a análise reflexiva dos sujeitos e de suas histórias, na direção da própria historicidade de quem narra e do que é narrado. Destarte, entende-se que as narrativas contribuem para a formação e para o desenvolvimento profissional dos professores, a partir das histórias de vida dos sujeitos. Logo, as histórias contadas contribuem para pensar os aspectos singulares e os coletivos que constroem e ressignificam a formação e a docência. Na continuidade, discorrer-se-ão sobre alguns instrumentos utilizados na pesquisa e na formação de professores.

\section{Técnicas e instrumentos que tecem e mobilizam as narrativas}

Diferentes técnicas e instrumentos são utilizados para estruturar e/ou registrar os relatos escritos das narrativas. Nesse sentido, elencam-se de forma sintética, algumas contribuições e características dos diários de aula, do memorial, da entrevista narrativa e das cartas para o fazer formativo e investigativo da narração, de acordo com as contribuições de Porlán e Martín (1997), Zabalza (2004), Abrahão e Passeggi (2010), Passeggi (2011), Jovchelovitch e Bauer (2010) e Camini (2012).

O diário de aula e as narrativas contidas nele, podem ser pensados como um instrumento teórico-metodológico capaz de mobilizar a reflexão sobre a pesquisa e a formação de professores. Segundo Porlán e Martín (1997, p. 18) o "[...] Diário de aula apresenta-se como instrumento que permite ao professor investigar e refletir sobre a prática educativa, testemunho biográfico da sua experiência”. Os autores destacam que a produção contínua dos diários pelos docentes corrobora que eles reflitam e reelaborem suas práticas em sala de aula. Nessa mesma perspectiva, Zabalza (2004, p. 13) afirma que "os diários de aula [...] são documentos em que professores e professoras anotam suas impressões sobre o que vai acontecendo em suas aulas [...]". Assim, o diário se configura como uma espécie de registro, de memória, que pode ser retomada, valorizando a ação reflexiva do professor.

Porlán e Martín (1997) entendem o diário de aula como um instrumento formativo. Zabalza (2004, p. 18) ainda destaca que as narrativas expressas nos diários constituem um registro variado em possibilidades de análise e que oferecem uma variedade de se pensar as dimensões pessoal e profissional dos sujeitos. Segundo o autor "torna-se [...] um grande recurso para explicar os próprios dilemas em relação à atuação profissional”. Portanto, o diário integra os processos das práticas docentes com a reflexão sobre o ensino-aprendizagem. 
Nesse sentido, Zabalza (2004, p. 16-27) elenca quatro dimensões de pesquisa e de formação a partir do diário, sendo elas:

1. O acesso ao mundo pessoal dos professores;

2. Os diários como um grande recurso para explicitar os próprios dilemas em relação à atuação profissional;

3. Os diários como recurso de acesso à avaliação e ao reajuste de processos didáticos;

4. Os diários como recurso para o desenvolvimento profissional permanente.

O diário de aula, a partir de um víeis da memória e da própria escrita, integram as dimensões do desenvolvimento pessoal com as práticas educativas, coadunando então, um conhecimento de/sobre si e a reflexão sobre o processo de ensino-aprendizagem, enquanto profissional. Logo, Zabalza (2004) entende a necessidade de se realizar um trabalho de pesquisa e de formação com os professores, a partir de seus diários, convidando os docentes a refletir sobre os desafios enfrentados e as representações que esses sujeitos fazem dele, visando à compreensão das práticas e das possibilidades de novos caminhos a serem traçados.

O memorial é um gênero textual que, como homonimamente é sugerido, é composto pela história de vida e por momentos elencados como marcantes pelo sujeito. Segundo Abrahão e Passeggi (2010), o memorial de formação no Brasil é produzido largamente nos anos de 1990, presente em diversos trabalhos científicos e em contextos formativos institucionais, com as perspectivas teóricas da (auto)biografia e das narrativas. O memorial é uma forma de sobrevivência e de registro de fatos e acontecimentos próprios do autor sobreviver ou perdurar frente ao esquecimento. A produção memorialística é rica de pontos que sinalizam processos de formação e de desenvolvimento, nos níveis pessoal e profissional e ainda, convida o interlocutor a embarcar naquela história contada. Assim, o memorial pode ser usado como um instrumento de formação, circunscrito a um período de tempo determinado, quando, por exemplo, é utilizado em uma disciplina específica ou em um período da escolarização, ou de forma mais ampliada, geral. Portanto, o memorial tem um vasto potencial formativo por agregar, a partir da narrativa de um sujeito, elementos dos desenvolvimentos, das práticas e das reflexões. Nessa direção, Passeggi (2011, p. 36) afirma que

O êxito da escrita do memorial se realizaria quando o autor explora o potencial da refletividade autobiográfica e se deixa envolver pelo encantamento estético e ético do fazer da vida intelectual e profissional um texto acadêmico como arte autoformadora de si mesmo como profissional.

Assim, as memórias de formação e de pesquisa, materializadas nas narrativas, fazem emergir vários elementos da história de vida e das trajetórias formativas. Bolívar (2002) destaca que as narrativas que retratam histórias pessoais, permitem também pensar em aspectos de natureza macro social, além de possibilitar revisitar as interações e as próprias práticas. As memórias são veículos de uma série de conhecimentos, reflexões, representações, imaginários e crenças que se intercruzam nas relações com o tempo e com as pessoas que figuram nas histórias narradas. Bolívar (2002) concordando com Nóvoa (1992) entende o memorial como um balanço da vida que fomenta os processos (auto)formativos a partir das trajetórias narrativas.

A entrevista narrativa é uma técnica de produção de dados que tem seu uso crescente nas pesquisas qualitativas no campo educacional e valoriza as dimensões de contar, de narrar uma história. De acordo com Jovchelovitch e Bauer (2010), a sistematização desse tipo de entrevista foi realizada por Schütze e valoriza que os sujeitos narrem episódios de suas vidas, conforme indicação temática sugerida pelo interlocutor, que assume um papel de escuta sensível frente a qualquer história contada, preservando a dinâmica da narrativa. Assim, Jovchelovitch e Bauer (2010, p. 93) afirmam que o intuito da entrevista narrativa é "[...] reconstruir acontecimentos sociais a partir da perspectiva dos informantes, tão diretamente quanto possível".

A entrevista narrativa se opõe a outras formas, como a semiestruturada, já que ela não é composta por uma lógica de perguntas ou respostas, mas sim, sugere eixos temáticos que permite ao interlocutor liberdade e fluidez para narrar. Jovchelovitch e Bauer (2010, p. 97) elencam que apesar da narrativa permitir maior espaço e maior protagonismo para o sujeito, a entrevista deve contemplar fases de um planejamento 
que constam as etapas de preparação, iniciação, narração central, perguntas e conclusão. Jovchelovitch e Bauer (2010, p. 106), a partir de Schütze (1997, p. 83), sugerem que o processo de análise das narrativas siga seis passos:

1. Transcrição detalhada de alta qualidade do material verbal.

2. Divisão do texto em material indexado (expressam referência concreta a "quem fez o quê, quando, onde e por quê") e proposições não-indexadas (que vão além do conhecimento e expressam valores, juízos e toda forma de uma generalizada "sabedoria de vida" dentre outros aspectos).

3. Uso de todos os componentes indexados para analisar o ordenamento dos acontecimentos para cada indivíduo, denominada de "trajetórias".

4. As dimensões não-indexados são investigativas como "análise do conhecimento" (opiniões, conceitos e teorias gerais, reflexões e divisões entre o comum e o incomum, que permitem reconstruir teorias operativas sobre o objeto de estudo).

5. Agrupamento e comparação das “trajetórias” individuais.

6. Trajetórias individuais colocadas dentro do contexto e semelhanças são estabelecidas permitindo a identificação de trajetórias coletivas.

As sugestões elencadas pelos autores permitem que o investigador compreenda por diversos prismas as narrativas e a questão de pesquisa. Pois, como já supracitado, a escolha e o enfoque pelas narrativas possibilitam as interseções entre os aspectos globais e singulares que atravessam e compõem as vidas narradas dos/pelos sujeitos. Evidenciando assim, os arranjos pessoais perante contextos sociais, políticos, históricos e econômicos que os indivíduos participam.

A carta é um gênero textual presente na história da humanidade por muitos séculos, trazendo informações tanto de cunho pessoal quanto oficial. Segundo Camini (2012), em função da tradição da cultura escrita das cartas e os seus conteúdos diversos, elas são consideradas fontes que possibilitam pensar o remetente, $o$ destinatário e o contexto que se vivia ou se falava. Nesse sentido, Lemos (2004) citado por Portal (2012, p. 79) afirmam que através das cartas "[...] ofende-se, apresenta-se, cobra-se, enfim, conjuga-se a infinidade de verbos que exprimem a riqueza contida no amplo contínuo que vai da trivialidade à nobreza da vida”.

Já como um dispositivo de formação, em função do seu modo de organização discursiva e o objetivo comunicativo predominante e, entendida a partir das lentes teórico-metodológicas da pesquisa narrativa, as cartas podem ser registros das trajetórias e, por conseguinte, material para a reflexão sobre a vida e sobre a formação. Camini (2012, p. 29-30) retrata como exemplo do uso pedagógico das cartas, as obras de Paulo Freire, Cartas à Guiné-Bissau (1978), Cartas a Cristina (1994) e Professora sim, tia não: cartas a quem ousa ensinar (2002), estabelecendo uma comunicação com o leitor a partir de suas práticas educativas. Camini (2012) destaca que as obras chamaram atenção por ressignificar os intuitos das comunicações por cartas, nos fazeres pedagógico e social, atingindo não apenas os principais destinatários, como no caso das duas primeiras obras, garantindo um caráter atemporal dos livros. Destarte, Portal (2012) entende as cartas, enquanto instrumento pedagógico, podem corroborar na constituição do professor, já que relatam práticas, espaços e memórias.

As histórias narradas pelos sujeitos compuseram a dinâmica realizada no âmbito do grupo de estudos e pesquisas FORMEPE. Em função do campo da formação de professores ser o ponto de interseção entre as proposições de pesquisa, em nível de mestrado, por parte dos autores, após apresentação teórica e metodológica dos objetivos da atividade, os sujeitos enviaram por um escrito, um texto livre, de uma passagem marcante no período da formação, quer seja, inicial ou continuada.

A proposição da dinâmica era de uma atividade que vislumbrasse unir diferentes pesquisas, no caso as investigações dos autores do presente texto, apresenta-las e mediar entre os demais integrantes a análise e a compreensão das narrativas sobre a formação. Como a confluência das temáticas se davam no campo da formação de professores e dos pressupostos teórico-metodológicos da pesquisa narrativa, a partir de uma sintética contextualização e apresentação de algumas categorias importantes das teorias preconizadas, partiu-se para a interlocução das histórias narradas pelos membros do grupo, em um movimento de interseção entre os aspectos singulares de cada trajetória, juntamente com elementos já presentes na literatura 
especializada. Portanto, foi pedido aos demais integrantes do grupo que preparassem uma narrativa, em formato livre, que versasse sobre alguma passagem de sua formação, quer seja inicial ou continuada, para a docência.

Após a realização dessa breve incursão, a pessoa, sujeito daquela narrativa, se apresentava enquanto ator-autor do relato, continuando o exercício reflexivo do diálogo com base nas experiências e nas pesquisas sobre formação de professores. Desse modo, após um breve panorama das pesquisas dos autores desse artigo e da apresentação dos pressupostos teóricos da pesquisa narrativa, que é comum aos três projetos, convidamos a cada participante que pudesse dividir sua história formativa conosco, tecendo comentários e interlocuções acerca do que fora narrado.

Assim, em termos metodológicos, nos orientamos pela perspectiva das narrativas, das histórias de vida, que partindo de trajetórias singulares, de experiências vividas, são debatidos os componentes relativos à formação, ao desenvolvimento e à aprendizagem profissionais da docência. Nesse sentido, na próxima seção, são apresentadas seis narrativas dos membros do FORMEPE, acompanhadas de dados de seus perfis biográficos, acerca de recortes de momentos significativos de sua formação. E em conjunto com as histórias, são apontadas algumas interlocuções teóricas, com a literatura especializada, com a finalidade de refletir sobre os elementos estruturais e comuns frente ao conhecimento produzido.

\section{Experiências, histórias e formações: narrativas dos participantes do grupo FORMEPE}

Nesta seção trataremos de apresentar e propor interlocuções a partir das seis narrativas de formação dos professores e das professoras do grupo. Com a descrição sintética do perfil do(a) autor(a) da narrativa e com a reelaboração, a reescrita das experiências compartilhadas, visamos a refletir sobre a formação, o desenvolvimento e as aprendizagens das docências.

A narrativa em questão diz respeito a um professor de História, formado no ano de 2017 pela Universidade Federal de Viçosa. Tem 25 anos de idade, estudou toda a vida em estabelecimentos escolares públicos e inclusive no ano de sua formação, atuou como professor na rede pública. Sobre essa experiência que ele constrói a narrativa. O chamaremos de Jorge. Ao ser solicitado que narrasse sobre um momento marcante durante sua formação, nos conta sobre dois momentos, o período de sua inserção profissional na docência e a realização do estágio de ensino, durante o mestrado.

A primeira situação relatada pelo professor, diz do momento em que ele assume a sala de aula, substituindo um professor, de forma que ele não inicia o ano letivo com os alunos, mas sim, os encontra no curso de seu processo de ensino aprendizagem iniciado naquele ano. Jorge relata que se vê diante do desafio de avaliar esses alunos. Quando questionado por eles “professor, quando é a prova?”, ele se dá conta de que não tinha se preparado para esse momento, se diz então tomado pelo medo de errar, e recorre às suas memórias como aluno, usando como referência a forma que fora avaliado no decorrer de sua vida como aluno e ainda, a modelos de provas retirados da internet.

Após a aplicação das provas, Jorge se vê diante do desafio de conferir valor, "nota" ao que foi avaliado e relata que adaptava esses valores, de acordo com o desempenho do aluno para além da prova, se se tratava de um aluno considerado por ele "esforçado", uma resposta incompleta poderia valer "1", mas se uma mesma resposta incompleta viesse de um aluno "não esforçado", poderia então valer 0 . O relato de Jorge sobre a divisão desigual de notas, ilustra uma situação comum vivenciada pelos professores, que, muitas vezes, não aprendem a avaliar durante sua formação inicial, uma vez que na maioria dos cursos de licenciatura, não existe uma disciplina voltada somente para a aprendizagem acerca da avaliação, por exemplo. De forma que os professores acabam por tomar como referência a forma como foram avaliados durante seu percurso acadêmico, muitos não compreendendo a atividade avaliativa como uma ferramenta de avaliação da aprendizagem, mas sim como uma oportunidade de punição ou de disciplinamento dos alunos. 
Jorge relata que mais tarde, ao iniciar o mestrado em educação, em uma disciplina de estágio da docência, realizada em uma disciplina específica de avaliação, ele passa a ter contato com o conteúdo e, refletindo sobre a sua prática e a aprendizagem construída durante a disciplina ele encontra "um porto seguro" para sua prática docente, ao se deparar com a existência de um referencial científico sobre "como deveriam se estruturar os processos avaliativos". Esse configura um segundo momento marcante em sua formação docente. Diante dessa aprendizagem, compreendendo a avaliação como um processo que deve ser claro e construído com o aluno, pareado com o decorrer da aprendizagem em sala de aula e não descolado dessa, Jorge reflete sobre a forma com qual conduziu a avaliação no ano anterior e percebe que se pautava muito mais em uma classificação dos alunos do que na avaliação de suas aprendizagens, no sentido de potencializá-las.

De acordo com Luckesi (2005), essa deve ser a direção da avaliação, na busca do melhor dos educandos, mais no sentido diagnóstico da aprendizagem para uma tomada de decisão do que em um sentido classificatório. O autor salienta que o momento da avaliação deve representar uma retomada de fôlego, uma pausa que possibilite a reflexão acerca das práticas pedagógicas. Embora, conforme menciona, Jorge tenha sido tomado por "raiva e tristeza" diante dessa reflexão, a mesma mobilizou nele o interesse de pesquisar sobre o tema durante o seu mestrado.

Dessa forma, ao compartilhar narrativamente suas experiências com a avaliação e as reflexões possibilitadas por essas experiências, o mestrando lança luz sobre esses momentos, os ressignificando. Demonstra o caráter cíclico da formação docente, que não se finda no curso de formação inicial, mas perdura durante a prática da profissão, na constituição de conhecimentos práticos em confluência com os conhecimentos teóricos que fundamentam a prática. Como esclarece Nóvoa "a formação vai e vem, avança e recua, construindo-se no interior de um processo de relação ao saber e ao conhecimento que se encontra no cerne da identidade pessoal" (NÓVOA, 1995, p. 25).

A narrativa conseguinte pertence a uma professora doutora e pesquisadora universitária, utilizaremos o pseudônimo Ângela, para preservar sua identidade. Ângela nasceu em uma cidade do interior de Minas Gerais, estudou durante toda a vida em escolas públicas, levando onze anos para concluir a educação básica. Solicitada a narrar sobre um evento marcante durante sua formação docente, a professora menciona que "busca revisitar e (re)conhecer o início da docência". Rememorar episódios marcantes ao decorrer da vida, é sobretudo uma forma de dar sentido a tudo o que foi vivido, dentre as inúmeras lembranças e possibilidades, e é o que pode ser observado durante a narrativa da professora, que, como a própria menciona, a partir de Dourado (1999), vai tirando de si o fio da própria teia, como uma aranha. Ao decorrer da narrativa, Ângela nos permite conhecer o emaranhado significativo de suas lembranças, entrecruzando episódios de sua formação na educação básica e a atuação como professora no magistério.

Ângela revisita suas memórias datando de 1985, quando conclui o Ensino Médio aos 17 anos e inicia o magistério. Ela menciona a realização dos estágios que compunham a inserção em escolas públicas, relembrando como a disciplina por parte dos alunos era algo esmerado à época. A professora menciona que foi bem avaliada durante os estágios de observação e que inclusive ouviu de seus professores que possuía "vocação" para o magistério. É interessante destacar que a docência foi vista, por muitos anos, como um ofício, como um trabalho abnegado, para o qual se tinha ou não vocação, o que, por muito tempo negou o caráter profissional desse trabalho, admitindo-se que bastava "nascer" apto ao exercício do magistério, dispensando assim uma formação profissional estruturada, pautada em conhecimentos.

Assim, Ângela nos remete a um momento importante no histórico de construção da carreira docente, em que o professor era visto como um indivíduo que nasceu fadado à cumprir esse ofício, o que por si só traz diversas outras implicações, como a identidade atrelada à profissão docente ao longo dos anos, como uma missão, um sacerdócio, um ofício que deve ser praticado, antes de tudo, com amor e abnegação.

Prosseguindo no fio de sua narrativa, a professora nos remete a um outro importante momento da trajetória de construção da identidade docente, a da feminização do magistério. Ângela menciona que apesar de ter corrido tudo bem no curso dos estágios e das disciplinas durante o magistério, esse na verdade não era um curso desejado por ela, não era sua escolha. De suas memórias a professora resgata o desejo de 
seguir outro percurso profissional, possivelmente matriculando-se em uma escola técnica no interior de Minas Gerais, mas que por essa ser preponderantemente masculina, não era uma opção para ela. Conforme relata, dadas as suas circunstâncias, de ser mulher, de família humilde e residente no interior, o magistério era sua única "oportunidade", e ao elegê-la, ela estaria seguindo o "destino" familiar das outras mulheres que a antecederam.

Assim, conforme descreve, a professora realiza o magistério em um misto de "gosto e de desilusão". Gosto por apreciar o processo de ensino aprendizagem proposto pelas disciplinas e desilusão por repetir "a sina familiar". Essa faceta da feminização docente, faz parte da identidade dessa profissão, sobretudo sobre a formação magisterial. Por muitos anos somente mulheres se formaram para serem professoras em anos iniciais da educação básica, sendo esse inclusive um dos primeiros ofícios permitidos à mulher na esfera pública, que outrora só dizia respeito ao homem. A mulher passa a sair de casa, da esfera privada, para a esfera pública da sala de aula e escolas, e embora essa saída tenha significado um grande avanço, ser professora "representava um prolongamento das funções domésticas e instruir e educar crianças, sob o mascaramento da missão da vocação inerente às mulheres significava uma maneira aceitável de sobrevivência" (ALMEIDA, 1996, p. 74). Dessa forma, o magistério representou por muito tempo uma "vocação" naturalmente feminina, apelando para um dado "instinto maternal", baseado somente no cuidado das crianças.

Prosseguindo em sua narrativa, a professora conta sobre sua inserção na docência, após formar-se no curso de magistério, inserção essa que ocorre na mesma escola pública do Ensino Fundamental em que Ângela estudara quando criança. Se tratava de uma escola multisseriada e contava, portanto, com uma realidade plural no contexto de uma mesma sala de aula, alunos em diferentes estágios de aprendizagem, de diferentes idades. A professora lembra inclusive de um aluno em específico que permaneceu anos na mesma escola, sem ter de fato aprendido quase nada. Nesse ponto, Ângela menciona em que se apoiava para dar conta do desafio de estar diante de 4 turmas de séries diferentes: Na experiência vivida e nos materiais das professoras anteriores, além disso, no material didático utilizado pelos alunos, sobretudo na alfabetização, que conforme relata, acontecia por meio do método silábico apresentado em cartilhas, um método de alfabetização que foi utilizado por muitos anos.

A professora rememora que reproduzia as mesmas atividades de quando era estudante, construindo a sua prática docente, tendo como base seus antigos professores, a forma como aprendeu durante sua trajetória escolar. Assim, conforme menciona "A docência ia sendo aprendida no percurso, na experiência, experimentando". Ângela termina sua narrativa rememorando a estrutura pobre da escola e ainda problemas de disciplina causados por alunos do "horário da tarde", lançando luz sobre mais um pouco dos desafios enfrentados por ela, jovem professora recém formada e aprendiz de sua profissão. Termina assim sua narrativa sem atar um nó, mas puxando outro fio do emaranhado de memórias de sua formação e atuação docente.

A narrativa a seguir foi sensibilizada pelo Matheus. O professor possui 25 anos, é licenciado em Química e natural de Matipó interior de Minas Gerais. Sua mãe, formada em magistério, o apresentou à docência bem cedo, ao longo de sua vida escolar. Matheus frequentou escolas públicas e privadas, seu Ensino Superior foi feito em uma instituição pública. Ao perguntarmos sobre o momento mais marcante de sua formação ele relata: "[...] O momento mais marcante da minha formação se deu na disciplina de Instrumentação para o Ensino II, na qual tive a oportunidade de tomar consciência e refletir sobre as minhas concepções de ciência, de ensino e educação".

Freire (1999, p. 43) afirma que "é pensando criticamente a prática de hoje ou de ontem que se pode melhorar a próxima prática”. Ao refletir, Matheus tomou consciência de suas concepções, mudando sua maneira de enxergar e quebrando barreiras intransponíveis até aquele instante acerca da ciência, ensino e educação como ele bem nos diz. O resultado é um novo olhar que envolve não só o momento relatado, mas sua posteridade. 
[...] a professora me surpreendeu ao levantar questões essenciais e importantes sobre a natureza da ciência e a especificidade do trabalho docente do professor de Ciências que me possibilitaram ressignificar toda a minha formação, com base numa nova concepção de conhecimento científico e, a partir disso, repensar a minha atuação futura enquanto professor, no sentido de promover uma prática mais adequada e articulada a uma proposta mais democrática e inclusiva do conhecimento científico. (Relato do professor Matheus).

O professor reflexivo ao refletir sua ação, sensibiliza seus alunos a fazerem o mesmo. A educação como ferramenta de emancipação é fluida, os conhecimentos ao serem ressignificados tecem novas percepções e saberes sensíveis ao aperfeiçoamento da formação docente. Tardif $(2002$, p. 54) informa que o "saber docente é um saber plural, formado de diversos saberes provenientes das instituições de formação, da formação profissional, dos currículos e da prática cotidiana". Entendendo isso, podemos dizer que Matheus experimentou algo rotineiro da formação docente, a oportunidade de se reinventar e enxergar a si e seus alunos como um ser inacabado em constante processo de construção.

Graduada em Educação Infantil, Bruna, de 30 anos, é natural de Ponte Nova, interior de Minas Gerais. Sempre estudou em escolas públicas e atualmente é servidora federal, atuando como técnica em assuntos educacionais.

Seguindo com as narrativas, iremos agora nos aproximar das impressões da formação inicial e continuada da integrante Bruna. Compartilhando sua experiência no estágio supervisionado II em um berçário de uma instituição de educação infantil, ela nos envolve com o quão desafiante pode ser a contação de histórias infantis para bebês: “[...] contar histórias para os bebês era algo em que eu tinha muita insegurança. Quais histórias contar? Como contar? Como os bebês vão reagir? Que recursos utilizar? Como conversar com os bebês e como eles vão me responder? Estas eram algumas das minhas indagações".

As inquietações relatadas fazem parte do profissional professor, receios que levam à constante busca do aprendizado. Neste cenário, Bruna entendeu logo muito cedo umas das lições mais bonitas e perturbadoras da docência: nunca estaremos integralmente prontos para todas as situações a nós colocadas, para todas as estratégias de ensino e tão pouco para o desconhecido que achou morada em nossa profissão; porém, estamos a todo momento ressignificando nossos conhecimentos e experiências em busca do melhor.

Freire (1991, p. 58) esclarece que "ninguém começa a ser educador numa certa terça-feira às quatro a tarde. Ninguém nasce educador ou marcado para ser educador. A gente se faz educador, a gente se forma, como educador, permanentemente, na prática e na reflexão sobre a prática”. Assim também corrobora Veiga (2008, p. 15): "o processo formativo assume uma posição de inacabamento, vinculada à história de vida dos sujeitos em permanente processo de formação, que proporciona a preparação profissional. O processo de formação é multifacetado, plural, tem início e nunca tem fim".

[...] O dia em que contei minha primeira história para os bebês foi mágico. Eles reagiram e interagiram de maneiras diferentes e especiais. Os bebês me mostravam a ludicidade naquela atividade quando sorriam à aproximação de um fantoche, quando arregalavam os olhos ao ouvir minhas imitações de sons dos personagens, quando acariciavam os fantoches ou quando tentavam colocá-los na boca, quando imitavam gestos, quando batiam palmas ao me ouvir cantando alguma música relacionada a história... até quando choravam devido a algum som. O sentimento de satisfação após contar a primeira história se repetiu nas demais vezes durante aquele estágio supervisionado. (Relato da professora Bruna).

A narrativa termina com Bruna demonstrando todo o contentamento em relação a sua experiência na contação de história e também sua superação ao que até aquele momento era um grande desafio. Pela sua experiência e superação entendemos que a prática aperfeiçoa a prática. A docência como profissão de múltiplas facetas nos ensina que as experiências se acumulam e os medos se transformam em aprendizado e em novas formas de ser e fazer a docência.

Já a narrativa Leila remetia ao início da docência, após o término do curso superior. A professora de 33 anos, mestre em Educação por uma Universidade Pública, atualmente atua no Ensino Superior, formando outros professores, conta da sua inserção na docência, atuando em conjunto com outra professora em uma 
instituição de educação infantil. Em meio aos medos e inseguranças que compõem o início da prática profissional, Leila narrou que por trabalhar em conjunto com uma docente considerada mais experiente, acabava por reproduzir, copiar as ações que a colega de profissão fazia, sem uma reflexão sobre a sua prática e ao seu próprio desenvolvimento profissional da docência.

Leila hoje reconhece sua atitude de forma crítica e indica que ao final do terceiro ano de sua atuação naquele estabelecimento escolar, percebeu que os desafios e as limitações de suas relações com as crianças e suas respectivas famílias advinham dos próprios entendimentos de docência que praticava enquanto professora. A partir desse momento, Leila considera que iniciou um processo de reflexão crítica quanto ao seu trabalho, observando as práticas pedagógicas de outras professoras da instituição, investindo em cursos de formação continuada, retomando leituras da época da graduação, o que fez mudar substancialmente suas relações em sala de aula, com as crianças e seus responsáveis. A professora avalia que hoje, enquanto formadora de outros professores, valoriza e entende que as experiências vividas também contribuem com a formação e o desenvolvimento da docência, sendo a atividade reflexiva, necessária aos processos de ensino-aprendizagem próprios da profissão, bem como, relacionados aos demais agentes da comunidade escolar.

Cabe destacar que, como ressalta Hall (2004), as identidades são formadas a partir das relações com os outros sujeitos e espaços, tendo como características principais a mudança e a pluralidade. Nesse sentido, Pereira e André (2017) chamam atenção para que, mesmo com os inúmeros desafios dados no período da formação inicial, o professor deve buscar a partir de um trabalho coletivo e colaborativo, compor e significar as próprias experiências para constituir suas identidades e suas práticas, como buscou Leila. Em termos dos aspectos do desenvolvimento profissional da docência, em acordo com Marcelo (2009), percebe-se que Leila não apenas iniciou processos formais de formação continuada, através de cursos, mas refletiu sobre suas práticas, levando em consideração, a interação e as relações com os seus interlocutores, bem como com as famílias, o que ilustra outros polos e conjunções que envolvem a docência.

Luísa, pedagoga e mestre em Educação, ambas por universidades públicas, trabalha atualmente como professora de séries iniciais em uma instituição privada. Quando provocada a pensar sobre uma experiência marcante na sua formação, rememorou a um evento do início da sua carreira como docente. A professora destacou antes que, mesmo sem formação universitária, já havia atuado como voluntária em projetos sociais que acolhiam crianças em situação de risco. Luísa retratou a experiência enquanto professora substituta em uma instituição federal de ensino básico, no mesmo período em que terminava o mestrado. Por se tratar de sua primeira experiência formal de docência, depois de sua formatura e por ser em uma instituição prestigiada na cidade, os sentimentos de ansiedade, nervosismo e insegurança estavam mais aflorados.

Nesse sentido, Luísa relatou sobre uma primeira reunião com pais e responsáveis da turma que lecionaria e que, frente a uma pergunta de uma das mães, sobre uma questão relativa a ortografia, ela não conseguiu responder prontamente. Mas, isso não aconteceu por não saber a matéria ou por uma dúvida, mas sim, por ter se sentido pressionada diante daquele contexto de reunião. Entretanto, outra professora que estava presente no encontro, percebendo o desconforto de Luísa, começou a explicar sobre o que fora perguntado, possibilitando que a docente pudesse contribuir ao longo da fala.

Dessa forma, Luísa reconhece a relevância de aspectos apontados por Vygotsky (1991), no campo da psicologia do desenvolvimento e da aprendizagem, como de Foerste (2005), na área de formação de professores, que apontam que a aprendizagem e o desenvolvimento, da docência no caso específico, acontecem e são fomentados no contato com o outro, com os pares, no decorrer das práticas educativas. Nessa direção, a professora consciente dos contextos de mudanças e de incertezas que envolvem a docência, investe na formação continuada para continuar refletindo sobre suas práticas.

As histórias contadas mobilizaram a partir das memórias, das lembranças experiências sobre a formação, ora inicial ora continuada, elencadas como marcantes pelos sujeitos que narraram os episódios. A partir das narrativas propõe-se um movimento de reflexão sobre as fases da formação, principalmente as retratadas e oferece com clareza, os elementos das trajetórias de vida e de escolarização que impactaram nas práticas enquanto estudantes e docentes. 


\section{Às guisas das considerações finais: pesquisa-formação com narrativas}

Analisando a potencialidade das narrativas na investigação, na formação e no desenvolvimento de/ sobre professores, entende-se que tal metodologia oferece protagonismo as experiências dos sujeitos, bem como para pensar a aprendizagem docente e o desenvolvimento profissional. O subsídio teórico concebe as narrativas como veículos para as compreensões das vidas pessoal e profissional, ecoa sobre a reflexão das práticas, vislumbra os contextos variados que os sujeitos reproduzem e representam que impactam na vida, na formação e na profissionalização.

Os relatos narrados sobre experiências formativas marcantes realizados pelos membros do grupo, principalmente relativas à formação inicial, que demonstraram inúmeros elementos sobre as trajetórias individuais, coletivas e educativas que refletem nas práticas profissionais, nas escolhas, nas motivações para os estudos e que impactaram os sujeitos a ter uma postura reflexiva e crítica, a partir do exercício da memória.

Os instrumentos e técnicas elencadas se apresentam enquanto possibilidades para se pensar e para compor as reflexões sobre si e sobre os demais. Por fim, acredita-se que as narrativas representam uma metodologia que analisa e compreende a formação e a investigação sobre o desenvolvimento profissional, ao passo que constroem aprendizados, questionamentos sobre a vida e a profissão, bem como da postura crítica frente à formação e à prática docentes.

\section{Referências}

ABRAHÃO, Maria Helena Menna Barreto; PASSEGGI, Maria da Conceição. As narrativas de formação, a teoria do professor reflexivo e a autorregulação da aprendizagem: uma possível aproximação. In: SIMÃO, Ana Margarida Vieira Veiga.; FRISON, Lourdes Maria Bragagnolo. Autorregulação da aprendizagem e narrativas autobiográficas: epistemologia e prática. Natal: EDUFRN; Porto Alegre: EDIPUCRS, 2012. p. 53-71.

ALMEIDA, Jane Soares de. Mulheres na escola: algumas reflexões sobre o magistério feminino. Caderno de Pesquisa, São Paulo, n. 96, p. 71-78, 1996.

BENJAMIN, Walter. O narrador: considerações sobre a obra de Nikolai Leskov. In: BENJAMIN, Walter. Obras escolhidas: magia e técnica, arte e política. v. 1. São Paulo: Brasiliense, 1993. p. 197-221.

BOLÍVAR, Antonio. Profissão professor: o itinerário profissional e a construção da escola. Bauru: EDUSC, 2002.

CAMINI, Isabela. Cartas pedagógicas: aprendizados que se entrecruzam e se comunicam. Porto Alegre: ESTEF, 2012.

CONNELLY, Michael; CLANDININ, Jean. Relatos de experiencia e investigación narrativa. In: LARROSA, Jorge (org.). Déjame que te cuente: ensayos sobre narrativa y educación. Barcelona: Laertes, 1995. p. 11-51.

DELORY-MOMBERGER, Christine. A pesquisa biográfica: projeto epistemológico e perspectivas metodológicas. In: ABRAHÃO, Maria Helena Menna Barreto; PASSEGGI, Maria da Conceição (org.). Dimensões epistemológicas e metodológicas da pesquisa (auto) biográfica. Natal: EDUFRN; Porto Alegre: EDIPUCRS; Salvador, EDUNEB, 2012. t. 1. p. 71-93.

DOURADO, Autran. O risco do bordado. 9. ed. Rio de Janeiro: Rocco, 1999.

FOERSTE, Erineu. Parceria na formação de professores. São Paulo: Cortez, 2005.

FREIRE, Paulo. Pedagogia da Autonomia: saberes necessários à prática educativa. São Paulo: Paz e Terra, 1999.

FREIRE, Paulo. A Educação na Cidade. São Paulo: Cortez, 1991.

GALZERANI, Maria Carolina Bovério. Percepções culturais do mundo da escola: em busca da rememoração. In: ENCONTRO NACIONAL DE PESQUISADORES DO ENSINO DE HISTÓRIA, 3., 1999, Campinas. Anais [...]. Campinas: Gráfica da Faculdade de Educação da UNICAMP, 1999. p. 99-108.

GOODSON, Ivor. Dar voz ao professor: as histórias de vida dos professores e o seu desenvolvimento profissional. In: NÓVOA, António (org.). Vidas de professores. Porto: Porto Editora, 1992. p. 63-78.

HALL, Stuart. A identidade cultural na pós-modernidade. 9. ed. Rio de Janeiro: DP\&A, 2004.

JOVCHELOVITCH, Sandra; BAUER, Martin. Entrevista Narrativa. In: BAUER, Martin; GASKELL, George (org.). Pesquisa qualitativa com texto, imagem e som: um manual prático. Petrópolis, RJ: Vozes, 2010. p. 90-113. 
LUCKESI, Cipriano Carlos. Avaliação da aprendizagem escolar: estudos e proposições. 17. ed. São Paulo: Cortez, 2005.

MARCELO, Carlos. Desenvolvimento Profissional Docente: passado e futuro. Revista de ciências da educação, São Paulo, n. 8, p. 7-22, jan./abr. 2009.

NÓVOA, António. Os professores e as histórias de vida. In: NÓVOA, António (org.). Vidas de professores. Porto: Porto Editora, 1992. p. 11-30.

NÓVOA, António (org.). Os professores e sua formação. 2. ed. Lisboa: Dom Quixote, 1995.

PASSEGGI, Maria da Conceição. Narrar é humano! Autobiografar é um processo civilizatório. In: PASSEGGI, Maria da Conceição; SILVA, Vivian Batista da (org.). Invenções de vidas, compreensão de itinerários e alternativas de formação. São Paulo: Cultura Acadêmica, 2010. p. 103-130.

PASSEGGI, Maria da Conceição. Injunção institucional e sedução autobiográfica: as faces autopoéticas e avaliativa dos memoriais In: BARBOSA, Tatyana Mabel Nobre.; PASSEGGI, Maria da Conceição (org.). Memorial acadêmico: gênero, injunção institucional, sedução autobiográfica. Natal: EDUFRN, 2011. p. 21-35.

PEREIRA, Marli Amélia Lucas; ANDRÉ, Marli. A formação inicial do professor e o desenvolvimento profissional docente. Devir Educação, Lavras, v. 1, n. 2, p. 5-18, 2017.

PORLÁN, Rafael; MARTÍN, José. El diário del professor: un recurso para la investigación en el aula. Sevilla: Díada, 1997.

PORTAL, Leda Lídia Franciosi. Cartas: um universo desvelador de significados na formação do formador? In: ABRAHÃO, Maria Helena Menna Barreto; FRISON, Lourdes Maria Bragagnolo (org.). Práticas docentes e práticas de (auto) formação. Natal: EDUFRN; Porto Alegre: EDIPUCRS, 2012. p. 79-105.

PRADO, Guilherme do Val Toledo; SOLIGO, Rosaura. Memorial de Formação: quando as memórias narram a história da formação... Campinas: UNICAMP, 2005. Disponível em: https://www.fe.unicamp.br/drupal/sites/www.fe.unicamp.br/ files/pf/subportais/graduacao/proesf/proesf_memoriais13.pdf. Acesso em: maio 2020.

SOUZA, Elizeu Clementino de. A caminho da roça: olhares, implicações e partilhas. In: SOUZA, Elizeu Clementino de (org.). Educação e ruralidades: memórias e narrativas (auto) biográficas. Salvador: EDUFBA, 2012. p. 17-28.

TARDIF, Maurice. Saberes docentes e formação profissional. 13. ed. Petrópolis: Vozes, 2002.

VEIGA, Ilma Passos Alencastro. Profissão docente: novos sentidos, novas perspectivas. Campinas: Papirus, 2008.

VYGOTSKY, Lev. A formação social da mente: o desenvolvimento dos processos psicológicos superiores. 4. ed. São Paulo: Martins Fontes, 1991.

ZABALZA, Miguel. Diários de aula: um instrumento de pesquisa e desenvolvimento profissional. Porto Alegre: ARTMED, 2004.

Data de submissão: 10/08/2020

Data de aceite: $27 / 09 / 2020$ 